\title{
The Effects of Pretreatment with Dipping Solution on Variation of Bos- calid Residue in Grape Samples During Drying Process with Natural Sunlight
}

\author{
Mustafa Cittan*, Ali Çelik, Kenan Dost \\ Manisa Celal Bayar University, Faculty of Science and Letters, 45140, Manisa, Turkey, Phone: +90 23620131 92, \\ mustafa.cittan@cbu.edu.tr \\ ali.celik@cbu.edu.tr \\ kenan.dost@cbu.edu.tr \\ *Corresponding author
}

Received: 13 December 2016

Accepted: 19 June 2017

DOI: $10.18466 /$ cbayarfbe.339312

\begin{abstract}
Field experiments were carried out to investigate the variation of boscalid level during the drying period in grape samples that were pretreated and untreated with a dipping solution named POTAS prior to natural sunlight drying. Grape samples were collected at harvest and on the $3^{\text {rd }}, 7^{\text {th }}$ and $10^{\text {th }}$ days after harvest (during the drying process of the pretreated and untreated grapes). Initially, 360 different pesticides were scanned qualitatively by GC-MS and LC-MS/MS after QuEChERS (Quick, easy, cheap, effective, rugged and safe) extraction method and only boscalid was observed in grape samples. Consequently, study was concentrated on boscalid extraction and analysis. Boscalid residues were extracted and cleaned up using QuEChERS method. The analysis method shows a good linearity over the concentration range of $0.010-0.125 \mathrm{mg} \mathrm{kg}^{-1}$ with a correlation coefficient value of 0.998 . Recoveries of the extraction and the analysis methods ranged from 74.8 to $100.8 \%$ within $0.7-1.7 \%$ RSD at three different concentration levels. Detection and quantification limits were 0.77 and $2.55 \mu \mathrm{g} \mathrm{kg}{ }^{-1}$, respectively. The uncertainty of the method was calculated as $0.100 \pm 0.040$ $\mathrm{mg} \mathrm{kg}^{-1}$. The results showed that grapes pretreated with the dipping solution prior to drying process showed shorter drying times and higher boscalid degradation rate than those untreated.
\end{abstract}

Keywords - Boscalid, degradation, GC-MS, QuEChERS, raisin

\section{Introduction}

Raisins are produced commercially by drying of harvested grapes. In order to dry grapes, water inside the grape must be removed completely from the interior of the cell onto the surface of the grape where the water droplets can evaporate. However, this diffusion process is very difficult because the grape skin contains wax in its cuticle, which prevents the water from passing through. In addition to this, the physical and chemical mechanisms located on the outer layers of the grape are adapted to prevent water loss [1].

Raisin, for fresh consumption as well as for using in baking and confectionery, is an important fruit because of its high nutritional value. Raisins are not only a good source for necessary vitamins and minerals, including potassium, iron, calcium, and vitamin B, but also fatless, cholesterol-free, and contain $70 \%$ fructose that is easily digestible [2]. The health benefits of raisins include relief from constipation, acidosis, anemia, fever, and sexual dysfunction. Raisins have also been known to help in attempts to gain weight in a healthy way, as well as its positive impact on eye health, dental care, and bone quality.

Raisins have a great economic importance for Turkey. The majority of seedless grapes are cultivated in the Aegean region in Turkey, especially in Manisa district. Therefore, drying of grapes is an important activity in the grape industry. Sun drying is the commonly employed method for this activity in Turkey. The harvested seedless grapes are traditionally pretreated with a dipping solution and then dried with natural sunlight on canvas sheets or concrete surfaces [3]. Pretreatment is a necessary step in raisin production in order to ensure the increased rate of water removal during the drying process. A faster water removal rate decreases 
the rate of browning and helps to produce more desirable raisins. The historical method of completing this process was developed in the Mediterranean and Asia Minor areas by using a dry emulsion cold dip made of potassium carbonate and olive oil. Conventionally used dipping solution is named POTAS and prepared by dissolving $0.5 \mathrm{~kg} \mathrm{~K}_{2} \mathrm{CO}_{3}$ in $10 \mathrm{~L}$ water and adding $0.05 \mathrm{~kg}$ olive oil. These methods can encourage water transfer to the outer surface of grapes which helps to increase the efficiency of the drying process. Although, the exact role of the constituents of the dipping solution is not fully understood, present knowledge indicates that the fatty acids mainly modify the outer wax layer while the POTAS neutralizes the free acids and their electrical charges in the cuticular membrane [4].

Due to the great economic importance of raisins for Turkey, the main aim here is to focus on increasing the efficiency of grape production in vineyards. Increasing agricultural productivity may require application of pesticides which are generally a chemical or biological agent that control the pests and diseases. Although pesticides have benefits, some also have drawbacks, such as potential toxicity to humans and other desired species. Their use must be controlled and employers should be aware of possible adverse effects on human health and the natural environment. Improper use of pesticides reduce agricultural sustainability by causing environmental problems such as underground and surface water pollution, destruction of beneficial organisms and acquirement of resistance by pests, and at the same time can have harmful effects on the health of both farmers and consumers [5].

Grapes contain high levels of sugars and other nutrients, low $\mathrm{pH}$ and ideal water activity for microbial growth that makes them particularly susceptible to fungal spoilage [6]. Therefore, the application of fungicides, as boscalid, is a common practice in the field. Boscalid [2-chloro-N-(4'chlorobiphenyl-2-yl) nicotinamide; $\mathrm{C}_{18} \mathrm{H}_{12} \mathrm{C}_{12} \mathrm{~N}_{2} \mathrm{O}$ ] (see Figure 1) is one of the most important fungicides used to destroy highly destructive plant pathogens, such as Botrytis cinerea in fruits and vegetables. It inhibits mitochondrial respiration, thereby inhibiting spore germination, germtube elongation, mycelial growth and sporulation of pathogenic fungi on the leaf surface [7].

A few numbers of analytical methods for the determination of residues of boscalid have been developed previously. Boscalid has been determined by using gas chromatography (GC) in various matrices by mass spectrometric (MS) detection $[8,9]$, and in blueberry samples by $\mu$-electron capture ( $\mu \mathrm{ECD}$ ) detection [10]. Determination of boscalid was also carried out by using liquid chromatography-tandem mass spectrometry (LC-MS/MS) [11,12].
In recent years simplification and increasing automation of sample preparation steps are one of the modern trends in analytical chemistry [13]. The traditional sample preparation methods used for extraction of pesticide residues in food matrixes are usually multi-stage procedures and require one or more cleanup steps. Therefore, they are timeconsuming, labour-intensive, complicated, expensive and produce considerable amounts of wastes. Quick, easy, cheap, effective, rugged and safe (QuEChERS) method is particularly popular for extraction of pesticide residues in food matrices [14-19] because of its simplicity, inexpensiveness, amenability to high throughput, and relatively high efficiency results with a minimal number of steps. The QuEChERS approach is very flexible and it serves as a template for modification depending on the analyte properties, matrix composition, equipment and analytical technique available in the lab [17]. This technique involves microscale extraction using acetonitrile and purifying the extract using dispersive solid-phase extraction (d-SPE) [19].

Boscalid is a certified pesticide in Turkey and is widely used by farmers in vineyards for protection against Botrytis cinerea. The aim of the study was to investigate the degradation rate of boscalid in respect to the time of sun drying process in pretreated and untreated grapes with the dipping solution.<smiles>O=C(Nc1ccccc1-c1ccc(Cl)cc1)c1cccnc1Cl</smiles>

Figure 1. Chemical structure of boscalid

\section{Material and Methods}

\subsection{Chemicals and reagents}

Reference standard of Boscalid was purchased from Dr Ehrenstorfer (Augsburg, Germany). QuEChERS extraction kits including anhydrous magnesium sulfate, sodium acetate and primary secondary amine (PSA) were obtained from Agilent Technologies (Wilmington, USA). HPLC grade acetonitrile and glacial acetic acid were supplied by Merck KGaA (Darmstadt, Germany). Acetone was of HPLC grade and obtained from Lab Scan (Sowinskiego, Poland). Distilled water was deionized by using a Milli-Q system from Millipore (Bedford, MA, USA). 


\subsection{Preparation of standard solutions}

The stock solution of boscalid was prepared by accurately weighing $5 \mathrm{mg}( \pm 0.01 \mathrm{mg})$ of boscalid in volumetric flasks (certified " $A$ " class) and dissolving in $10 \mathrm{~mL}$ acetone. This solution was stored in dark at $4{ }^{\circ} \mathrm{C}$. The standard solutions of boscalid used to make the calibration graphs and validation of method were prepared before use by dilution of the calculated volume of stock solution to appropriate volume.

\subsection{Instrumentation}

GC analyses were performed with a Shimadzu GC-2010 Plus (Shimadzu, Japan) gas chromatography system hyphenated to a MS-QP2010 Ultra (Shimadzu, Japan) mass spectrometer. A Rtx-CLPesticides 2 column (20 m x 0.10 mm I.D. and film thickness $0.14 \mu \mathrm{m}$ ) was used. The PTV injector was operated at $250{ }^{\circ} \mathrm{C}$. The ion source and the transfer line temperatures were set at 220 and $250{ }^{\circ} \mathrm{C}$, respectively. The sample $(1 \mu \mathrm{L})$ was injected in splitless mode with a constant flow rate of carrier gas at $1.4 \mathrm{~mL} \mathrm{~min}^{-1}$ and the oven temperature program was started as follows: 115 ${ }^{\circ} \mathrm{C}$ for $2 \mathrm{~min}$, increasing to $250^{\circ} \mathrm{C}$ by a ramp of $25^{\circ} \mathrm{C}$ min ${ }^{1}$. Finally $12^{\circ} \mathrm{C} \min ^{-1}$ ramp was applied until $300^{\circ} \mathrm{C}$. Centrifugation was performed by using Nüve CN 180 (Ankara, Turkey) centrifuge.

\subsection{Raisin preparation}

Harvesting and drying of the grapes were performed at Manisa Viticulture Research Station Headship. Grape samples used in this study were collected during the harvest. The collected grape samples were then divided in to two groups. While one of this groups was pretreated with the dipping solution prior to drying, but the other group was not. Approximately $100 \mathrm{~g}$ portions of both groups (treated and untreated with dipping solution) were transferred to the laboratory at harvest (before drying process) and on chosen days during the drying period ( $3^{\text {rd }}, 7^{\text {th }}$ and $10^{\text {th }}$ days after harvest). After the $10^{\text {th }}$ days of drying (when the drying process was completed), both raisin samples were transferred to the laboratory and stored for 6 months to determine the degradation level of boscalid residues in respect to the storage time. All the samplings were performed in triplicate.

The transferred grape samples were scanned by GC-MS and LC-MS/MS for qualitative determination of 360 pesticides, and only boscalid was observed in grape samples. Consequently, the following sections contain only the information about extraction, analysis and discussion of boscalid.

\subsection{Sample preparation procedure}

The QuEChERS extraction method is designed for pesticide extraction of fruits and vegetables with high water content. If an extraction of commodities with low-water content is studied, an addition of water is necessary for an efficient extraction. Consequently, in our extraction study, $15 \mathrm{~g}$ portion of the samples collected at harvest and $3^{\text {rd }}$ day of drying on sun light were extracted directly without any water addition due to they contained sufficient water. For $7^{\text {th }}$, $10^{\text {th }}$ days of drying on sunlight and stored samples (6 months), $5 \mathrm{~g}$ of water was added to $10 \mathrm{~g}$ of samples (in total $15 \mathrm{~g}$ ) due to water loss of the grapes during drying period. The samples transferred to the laboratory were firstly homogenized and a $15 \mathrm{~g}$ of homogenized sample was placed into a $50 \mathrm{~mL}$ centrifuge tube. A $15 \mathrm{~mL}$ of $1 \%$ acetic acid in acetonitrile was then added into the centrifuge tube and vortexed for $1 \mathrm{~min}$. In the next step, anhydrous $\mathrm{MgSO}_{4}(6.0 \mathrm{~g})$ and $\mathrm{NaOAc}(1.5 \mathrm{~g})$ were added directly into the tubes. The centrifuge tubes were sealed tightly and shaken vigorously for $1 \mathrm{~min}$ by hand to ensure that the solvent was interacted with the entire sample and crystalline agglomerates were dispersed. The content of the tube was then centrifuged at $3000 \mathrm{rpm}$ for $5 \mathrm{~min}$.

The extract contains co-extracted compounds. Subsequently, the dispersive SPE procedure was applied to clean up the extract. In this procedure, a $6 \mathrm{~mL}$ aliquot of supernatant was transferred into a tube containing $400 \mathrm{mg}$ of PSA and $1200 \mathrm{mg}$ of anhydrous $\mathrm{MgSO}_{4}$. The tubes were then tightly capped and vortexed for $1 \mathrm{~min}$. The extract was centrifuged at $3000 \mathrm{rpm}$ for $5 \mathrm{~min}$ and finally $1.5 \mathrm{~mL}$ extracted solution was placed into the GC vial to carry out the chromatographic analysis.

\section{Results and Discussion}

\subsection{Determination, recovery and uncertainty}

The linearity of the analysis method was quite good over concentration range of $0.010-0.125 \mathrm{mg} \mathrm{kg}^{-1}$ given a correlation coefficient $\left(R^{2}\right)$ of 0.998 . The recovery of the method was evaluated by spiking control samples with boscalid at three concentration levels (at low, middle and high concentrations of the calibration graph). The results of the recovery studies are presented in Table 1. Average boscalid recovery results in GC-MS for the QuEChERS spiked at $0.010 \mathrm{mg}$ $\mathrm{kg}^{-1}, 0.050 \mathrm{mg} \mathrm{kg}^{-1}$ and $0.100 \mathrm{mg} \mathrm{kg}^{-1}$ were $86.1,74.8$ and $100.8 \%$ with $0.7,1.2$ and $1.7 \%$ RSD respectively $(n=3)$. Similar recoveries have been reported by Lagunas et al. [20].

Table 1. Recovery of boscalid in grape samples

\begin{tabular}{|c|c|c|c|}
\hline Conc. (mg kg${ }^{-1}$ ) & Recovery (\%) & RSD (\%) & Rep. \\
\hline 0.010 & 86.1 & 0.7 & 3 \\
\hline 0.050 & 74.8 & 1.2 & 3 \\
\hline 0.100 & 100.8 & 1.7 & 3 \\
\hline
\end{tabular}

Conc., concentration; RSD, relative standard deviation and Rep., replicates. 
The uncertainty of the method was calculated as $0.100 \pm$ $0.040 \mathrm{mg} \mathrm{kg}^{-1}$. This value was calculated using the bottomup approach by taking in account of all the uncertainty of the both extraction and analysis methods, such as, uncertainty in weighting and pipetting, volume of extraction solvent, repeatability, recovery and calibration graph [21].

The overall combined uncertainty of the used method could be calculated using the following equation:

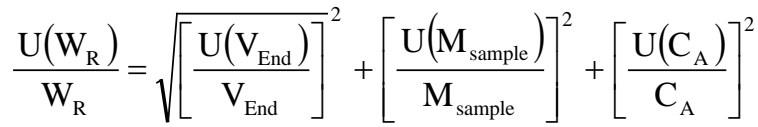

$$
\begin{aligned}
& +\left[\frac{\mathrm{U}(\mathrm{Rec})}{\mathrm{Rec}}\right]^{2}+\mathrm{U}(\text { Repeat })^{2}
\end{aligned}
$$

where, $\mathrm{W}_{\mathrm{R}}$ is the amount of boscalid residues in grape samples in $\mathrm{mg} \mathrm{kg}^{-1} ; \mathrm{C}_{\mathrm{A}}$ is the concentration of the boscalid in the sample solution in $\mathrm{mg} \mathrm{L}^{-1} ; \mathrm{V}_{\text {End }}$ is the volume of the sample solution in $\mathrm{mL}$; $\mathrm{M}_{\text {Sample }}$ is the sample mass in g; Rec is the recovery [13].

The limit of detection (LOD) and quantification (LOQ) of the method including QuEChERS and GC-MS were calculated as three and ten times the signal-to-noise ratio, respectively. The LOD was 0.77 and LOQ was $2.55 \mu \mathrm{g} \mathrm{kg}^{-1}$. These values satisfy the MRLs established by the European Commission (EC) and means that the method is sufficiently sensitive. The LOD and LOQ of our method were lower than those obtained by Čuš et al. [22] and Munitz et al. [10]. In addition, Pizzutti et al. [23] developed a more sensitive methodology based on liquid extraction and HPLC-MS/MS detection for soya grains, where the LOD was lower than $0.25 \mu \mathrm{kg}^{-1}$.

\subsection{Variation of boscalid residue levels}

Results of boscalid variation in grape samples are presented in Table 2 and Figure 2. Values reported are means of three parallel samples that were analyzed in triplicate. The initial deposits of boscalid were $0.032 \pm 0.013$ and $0.016 \pm 0.006 \mathrm{mg}$ $\mathrm{kg}^{-1}$ for grapes were pretreated and untreated with the dipping solution, respectively. Boscalid residue level in grapes which were pretreated with the dipping solution after harvest were higher than those untreated samples. This can be attributed to the accumulation of boscalid in the dipping solution, because of repeated use, and the adsorption of the boscalid on grape surfaces during the dipping pretreatment.

Increases in the level of boscalid were observed due to loss of water until the $7^{\text {th }}$ day of harvest in both grape samples pretreated and untreated with the dipping solution prior to drying process. Although, the amount of boscalid were decreased in both groups of the samples between the $7^{\text {th }}$ and the $10^{\text {th }}$ days of harvest, the reduction was occurred more significantly in grape samples that were pretreated with the dipping solution.

After 6 months the level of boscalid in grape samples pretreated with the dipping solution decreased below the limit of detection of the method. But in grape samples which were not treated with the dipping solution reached approximately initial value of fresh grapes at harvest.

Table 2. Variation of boscalid residue levels on grape samples depending on time and dipping solution, $(n=3)$

\begin{tabular}{|l|c|c|}
\hline \multirow{2}{*}{ Days } & \multicolumn{2}{|c|}{ Boscalid concentration $\left(\mathrm{mg} \mathrm{kg}^{-1}\right)$} \\
\cline { 2 - 3 } & $\begin{array}{c}\text { Grapes pre- } \\
\text { treated with dip- } \\
\text { ping solution }\end{array}$ & $\begin{array}{c}\text { Untreated } \\
\text { grapes }\end{array}$ \\
\hline At harvest & $0.032 \pm 0.013$ & $0.016 \pm 0.006$ \\
\hline $3^{\text {rd }}$ of harvest & $0.037 \pm 0.015$ & $0.033 \pm 0.013$ \\
\hline $7^{\text {th }}$ of harvest & $0.079 \pm 0.032$ & $0.076 \pm 0.031$ \\
\hline $10^{\text {th }}$ of harvest & $0.029 \pm 0.012$ & $0.066 \pm 0.026$ \\
\hline $\begin{array}{l}180^{\text {th }} \text { of harvest } \\
(6 \text { months })\end{array}$ & $<\mathrm{LOD}$ & $0.013 \pm 0.005$ \\
\hline
\end{tabular}

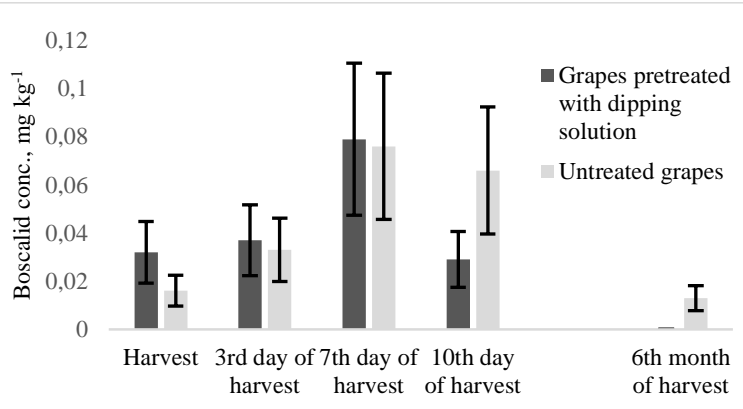

Figure 2. Variation of boscalid residue levels in grapes pretreated with the dipping solution and untreated grapes

\section{Conclusions}

It was found that, boscalid level in grapes began to increase due to loss of water while drying process until the $7^{\text {th }}$ day for both pretreated and untreated grapes with the dipping solution. Boscalid level decreased for a value of 63 and 13\% between the $7^{\text {th }}$ and the $10^{\text {th }}$ days of harvest (during the drying period) in grape samples that were pretreated and untreated with the dipping solution, respectively. Higher degradation rate in pretreated grape samples is attributed to the effect of chemical composition of the pretreatment solution on boscalid structure.

It has been discussed in the literature that boscalid undergoes photolytic and metabolic degradation in various me- 
dia. According to the literature and our knowledge, photolytic degradation is more favorable due to exposure of grape samples to the sunlight during the drying period. Eight photoproducts were characterized by Lassalle et al. [24] Higher degradation rate in pretreated grape samples is the result of the dipping solution which accelerates the photolytic degradation of boscalid by the effect of high alkaline content $(\mathrm{pH} \approx 12)$. Because, it is well known that, in basic solution the chloropyridine groups are attacked by hydroxide group [25] and amido groups undergoes basic hydrolysis [26]. After that, the compound is considered to undergo metabolic degradation during the storage period.

After 6 months from harvest, boscalid level in grape samples pretreated with the dipping solution decreases below the limit of detection of the method due to the degradation of boscalid in time. Similar degradation of boscalid was also observed for the grapes which were untreated with the dipping solution, but degradation rate was lower than those pretreated. This result proves that the pretreatment with the dipping solution causes not only accelerate the drying process, but also increases the degradation of boscalid in grapes with the support of sunlight. Merchants who dry grapes should take this into consideration.

\section{Acknowledgments}

M. Cittan thanks TÜBİTAK for scholarship (BİDEB 2211A).

\section{References}

1. Esmaiili, M, Sotudeh-Gharebagh, R, Cronin, K, Mousavi, M.A.E, Rezazadeh, G, Grape Drying: A Review, Food Reviews International, 2007, 23, 257-280.

2. Sanz, M.L, del Castillo, M.D, Corzo, N, Olano, A, Formation of Amadori Compounds in Dehydrated Fruits, Journal of Agricultural and Food Chemistry, 2001, 49, 5228-5231.

3. Doymaz, İ, Pala, M, The effects of dipping pretreatments on air-drying rates of the seedless grapes, Journal of Food Engineering, 2002, 52, 413417.

4. Christensen, L.P, Raisin Production Manual; University of California. UCANR Publications, 2000.

5. Isin, S, Yildirim, I, Fruit-growers' perceptions on the harmful effects of pesticides and their reflection on practices: The case of Kemalpasa, Turkey, Crop Protection, 2007, 26, 917-922.

6. Tournas, V.H, Katsoudas, E, Mould and yeast flora in fresh berries, grapes and citrus fruits, International Journal of Food Microbiolgy, 2005, $105,11-17$.

7. Avenot, H.F, Michailides, T.J, Resistance to Boscalid Fungicide in Alternaria alternata Isolates from Pistachio in California, Plant Disease, 2007, 91, 1345-1350.

8. Reilly, T.J, Smalling, K.L, Orlando, J.L, Kuivila, K.M, Occurrence of boscalid and other selected fungicides in surface water and groundwater in three targeted use areas in the United States, Chemosphere, 2012, 89, 228234.

9. Machado, I, Gérez, N, Pistón, M, Heinzen, H, Cesio, M.V, Determination of pesticide residues in globe artichoke leaves and fruits by GC-MS and LC-MS/MS using the same QuEChERS procedure, Food Chemistry, 2017, 227, 227-236.

10. Munitz, M.S, Resnik, S.L, Montti, M.I.T, Method development and validation for boscalid in blueberries by solid-phase microextraction gas chromatography, and their degradation kinetics, Food Chemistry, 2013, 136, 1399-1404.

11. Arienzo, M, Cataldo, D, Ferrara, L, Pesticide residues in fresh-cut vegetables from integrated pest management by ultra performance liquid chromatography coupled to tandem mass spectrometry, Food Control, 2013, 31, 108-115.

12. Souza, D, Souza, E, Borges, E, Determination of Pesticides in Grape Juices by QuEChERS and Liquid Chromatography-Tandem Mass Spectrometry, Journal of the Brazilian Chemical Society, 2016, 27, 16261635.

13. Pelit, F.O, Pelit, L, Ertaş, H, Ertaş, F.N, Development of a gas chromatographic method for the determination of Chlorpyrifos and its metabolite Chlorpyrifos-oxon in wine matrix, Journal of Chromatography B, 2012, 904, 35-41.

14. Banerjee, K, Oulkar, D.P, Dasgupta, S, Patil, S.B, Patil, S.H, Savant, R, Adsule, P.G, Validation and uncertainty analysis of a multi-residue method for pesticides in grapes using ethyl acetate extraction and liquid chromatography-tandem mass spectrometry, Journal of Chromatography A, 2007, 1173, 98-109.

15. Gilbert-López, B, García-Reyes, J.F, Lozano, A, Fernández-Alba, A.R, Molina-Díaz, A, Large-scale pesticide testing in olives by liquid chromatography-electrospray tandem mass spectrometry using two sample preparation methods based on matrix solid-phase dispersion and QuEChERS, Journal of Chromatography A, 2010, 1217, 6022-6035.

16. González-Curbelo, M.Á, Hernández-Borges, J, Ravelo-Pérez, L.M, Rodríguez-Delgado, M.Á, Insecticides extraction from banana leaves using a modified QuEChERS method, Food Chemistry, 2011, 125, 10831090.

17. Lehotay, S.J, Son, K.A, Kwon, H, Koesukwiwat, U, Fu, W, Mastovska, K, Hoh, E, Leepipatpiboon, N, Comparison of QuEChERS sample preparation methods for the analysis of pesticide residues in fruits and vegetables, Journal of Chromatography A, 2010, 1217, 2548-2560.

18. Sirhan, A.Y, Tan, G.H, Wong, R.C.S, Method validation in the determination of aflatoxins in noodle samples using the QuEChERS method (Quick, Easy, Cheap, Effective, Rugged and Safe) and high performance liquid chromatography coupled to a fluorescence detector (HPLC-FLD), Food Control, 2011, 22, 1807-1813.

19. Wilkowska, A, Biziuk, M, Determination of pesticide residues in food matrices using the QuEChERS methodology, Food Chemistry, 2011, 125, 803-812.

20. Lagunas-Allué, L, Sanz-Asensio, J, Martínez-Soria, M.T, Comparison of four extraction methods for the determination of fungicide residues in grapes through gas chromatography-mass spectrometry, Journal of Chromatography A, 2012, 1270, 62-71.

21. Ellison, S.L.R, Quantifying Uncertainty in Analytical Measurement, EURACHEM/CITAC Guide, 2nd ed., 2000. 
22. Čuš, F, Česnik, H.B, Bolta, Š.V, Gregorčič, A, Pesticide residues and microbiological quality of bottled wines, Food Control, 2010, 21, 150154

23. Pizzutti, I.R, de Kok, A, Hiemstra, M, Wickert, C, Prestes, O.D, Method validation and comparison of acetonitrile and acetone extraction for the analysis of 169 pesticides in soya grain by liquid chromatographytandem mass spectrometry, Journal of Chromatography A, 2009, 1216 4539-4552.

24. Lassalle, Y, Kinani, A, Rifai, A, Souissi, Y, Clavaguera, C, Bourcier,
S, Jaber, F, Bouchonnet, S, UV-visible degradation of boscalid--structural characterization of photoproducts and potential toxicity using in silico tests, Rapid Communications in Mass Spectrometry, 2014, 28, 1153-1163.

25. Reinheimer, J.D, Mayle, L.L, Dolnikowski, G.G, Gerig, J.T, Reaction of 2-halo-5-nitropyridines with hydroxide ion in dimethyl sulfoxide, The Journal of Organic Chemistry, 1980, 45, 3097-3100.

26. Gassman, P.G, Hodgson, P.K.G, Balchunis, R.J, Base-promoted hydrolysis of amides at ambient temperatures, Journal of American Chemical Society, 1976, 98, 1275-1276. 